\title{
Prevalence and predictors of neoaortic regurgitation after arterial switch operation for transposition of the great arteries
}

\author{
Roberto Formigari, MD, FACC \\ Alessandra Toscano, $\mathrm{MD}^{\mathrm{b}}$ \\ Alessandro Giardini, MD ${ }^{\mathrm{a}}$ \\ Gaetano Gargiulo, MD ${ }^{\mathrm{a}}$ \\ Roberto Di Donato, MD \\ Fernando M. Picchio, MD, FESC ${ }^{\mathrm{a}}$ \\ Luciano Pasquini, MDa
}

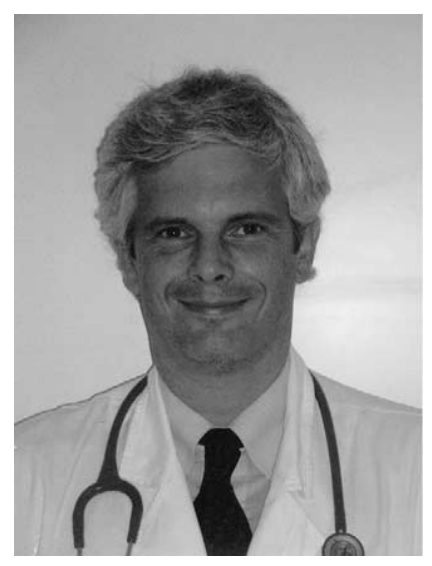

\footnotetext{
From Pediatric Cardiology and Cardiac Surgery, ${ }^{\text {a }}$ University of Bologna, Bologna, Italy, and Pediatric Cardiology and Cardiac Surgery, "Bambino Gesù" Hospital, Rome, Italy.

Presented at the Fiftieth Annual Scientific Session of the American College of Cardiology, Orlando, Fla, March 2001.

Received for publication Jan 20, 2003; revisions requested Feb 14, 2003; revisions received April 1, 2003; accepted for publication June 25, 2003.

Address for reprints: Roberto Formigari, MD, FACC, Policlinico S. Orsola, Cardiologia e Cardiochirurgia Pediatrica, Via Massarenti 9, 40138 Bologna, Italy (Email: r.formigari@mclink.it).

J Thorac Cardiovasc Surg 2003;126:1753-9

Copyright (C) 2003 by The American Association for Thoracic Surgery

$0022-5223 / 2003 \$ 30.00+0$

doi:10.1016/S0022-5223(03)01325-4
}

Background: The fate of the native pulmonary valve after arterial switch operation is still unknown and may become a cause for a secondary aortic valve operation during adult life. We evaluated the prevalence and predictive factors associated with neoaortic valvular regurgitation by a retrospective study of children who underwent arterial switch operation for transposition of the great arteries.

Methods: The onset of neoaortic valvular regurgitation was correlated with demographic data, cardiac anatomy, surgical technique, and postoperative ventricular function. The size of the neoaortic root and ascending aorta was measured in a selected subset of patients.

Results: Among 253 survivors, 173 were eligible for the study. After a median follow-up time of 8.2 years, 61 patients showed echocardiographic or angiographic evidence of valvular incompetence, which was progressive in 14 cases; this led to surgical intervention in 2 patients, and there was 1 operative death. At multivariate analysis, the onset of valvular regurgitation was correlated with the trap-door technique for coronary reimplantation $(P<.01)$. A smooth transition from the aortic sinus to the ascending aorta, with loss of the normal sinotubular junction geometry, may be associated with valvular incompetence.

Conclusions: After arterial switch operation, there is an increasing frequency of neoaortic regurgitation, which may lead to significant valvular dysfunction later in life. The trap-door type of coronary reimplantation is associated with an increased risk for valvular dysfunction, possibly because of a distortion of the sinotubular junction geometry. For this reason, we recommend the punch technique for repair in all but the most complicated coronary pattern.

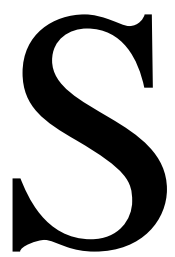

ince the original report by Jatene and colleagues, ${ }^{1}$ the arterial switch operation (ASO) has become the procedure of choice for neonates with transposition of the great arteries (TGA). Nevertheless, there is still some concern about the long-term outcome of these patients, particularly in regard to the potential for coronary insufficiency, ${ }^{2,3}$ left ventricular dysfunction, ${ }^{4}$ and ventricular outflow tract obstruction. ${ }^{5-8}$ Surprisingly, the conversion of the native pulmonary valve into a neoaortic valve has rarely been identified as a potential long-term risk factor. Only one recent study reported that neoaortic regurgitation (NeoAR) may, indeed, develop progressively over time, reaching a $30 \%$ incidence 6 years after ASO. ${ }^{8}$ Should the issue of NeoAR become of greater magnitude with longer follow-up intervals, an increasing number 


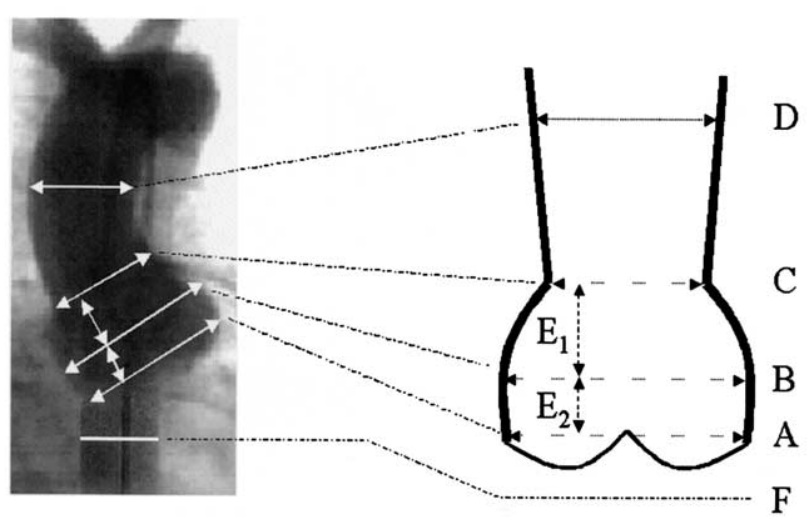

Figure 1. Morphometric assessment of the neoaorta after arterial switch operation. The measurements were taken at the level of the ascending aorta (D), sinotubular junction (C), neoaortic sinus (B), and semilunar leaflets (A). The height of the sinotubular junction was measured as $E 1$ and $E 2$. All values were normalized against the measurement of the normal descending aorta (F).

of patients might require a secondary aortic valve operation in the future. The aim of this study was to investigate anatomic and surgical factors possibly predisposing to NeoAR by a retrospective review of a large group of patients who received ASO in 2 pediatric cardiac centers.

\section{Patients and Methods \\ Patient Population}

Between January 1987 and January 2001, 288 patients underwent ASO at the 2 institutions involved in the study. The overall mortality was $12.1 \%$ over the entire 14 -year experience. Cumulative mortality decreased to $6.3 \%$ during the last 5 years (19962001 ) and to less than $2 \%$ in the last 2 years. Of the 253 patients who survived the operation, 173 had complete and reliable follow-up records and form the study population.

\section{Surgical Technique}

Moderately hypothermic extracorporeal circulation at $24^{\circ} \mathrm{C}$ was the preferred method of perfusion at both institutions. Circulatory arrest with selective cannulation of the innominate artery and low-flow cerebral perfusion at $20^{\circ} \mathrm{C}$ was usually performed if an aortic arch operation was needed. The Lecompte maneuver was performed with generous dissection of the pulmonary arteries. The coronary arteries were dissected free, and small collateral branches were sacrificed if they were suspected to cause distortion of the anastomoses. Two different strategies for coronary reimplantation were adopted: (1) the creation of 2.7-mm holes within the aortic wall and relocation of the coronary buttons proximal to the sinotubular junction (STJ; punch technique; $51 \%$ of the study population) or (2) the creation of a medially based trap-door flap rotated to open a space for coronary reimplantation (trap-door technique; $49 \%$ of the study population) without tissue excision from the proximal neoaorta. Patient selection in respect to the coronary relocation technique was different between the 2 institutions involved in the study. In one institution, the punch technique has been the method of choice since 1995, and the trap-door technique was limited to the patients operated on before 1995 or those with a single coronary orifice or an intramural course. In the other institution, the trap-door technique has been most often applied throughout their experience regardless of the coronary artery anatomy. The pulmonary trunk was always repaired with a pantaloonshaped patch of autologous pericardium. An additional operation (besides ventricular septal defect [VSD] patch closure, pulmonary artery debanding, or both) was needed in 14 patients (aortic coarctation repair in 8 , resection of the infundibular septum in 4 , pulmonary artery plasty in 1 , and mitral valve cleft repair in 1).

\section{Follow-up Protocol}

Routine clinical and echocardiographic evaluation was performed 3 months after the operation and yearly thereafter in both centers. The echocardiographic assessment was performed with HewlettPackard Sonos 2500 (Hewlett-Packard, Palo Alto, Calif) and Agilent 5500 (Agilent Technologies, Palo Alto, Calif) models. Control cardiac catheterization and angiography in all patients who have undergone ASO between 1 and 3 years after the operation or earlier in case of branch pulmonary artery stenosis or residual defects has been the policy adopted by the 2 institutions since the beginning of the experience with anatomic repair of transposition. Overall, 152 patients had invasive postoperative studies at $4.0 \pm$ 3.2 years (mean $\pm \mathrm{SD}$ ) after the operation. The remaining 21 patients either refused control cardiac catheterization or are currently waiting for it.

\section{Data Analysis}

The clinical records were retrospectively reviewed to detect the onset, severity, and progression of valvular regurgitation or ventricular dysfunction. A review of previously recorded VHS tapes was needed in 47 patients to clarify the time of onset and severity of NeoAR or to assess left ventricular ejection fraction at the latest follow-up (calculated by the Teicholz, biplane area length, or Bullet method). The selection criterion was the presence of NeoAR, regardless of the magnitude of valvular incompetence. Valve incompetence was graded according to the scale of Galassi and associates. ${ }^{9}$ An ejection fraction value of less than $50 \%$ was considered suggestive of poor left ventricular performance. The surgical records were reviewed in regard to cardiac anatomy, coronary pattern, presence of bicuspid pulmonary valve, and other variables, eg, weight at operation and type of surgical technique. Among the variety of coronary patterns, usually described by either the Leiden or the Yacoub classification, a dichotomous variable was created to simplify the multivariate analysis: a complicated coronary pattern (single coronary orifice, or with intramural course) versus a simple one (all others).

Angiographic studies, when available, were reviewed for confirmation of the echocardiographic findings concerning the degree of regurgitation (if present) and ventricular function. Valve regurgitation was classified as trivial, mild, moderate, or severe. ${ }^{10}$ In 131 cases, the quality of the angiographic pictures allowed the assessment of the dimensions of the neoaortic valve, the sinuses of Valsalva, the STJ, and the ascending aorta, as described by Kunzelman and colleagues ${ }^{11}$ (Figure 1), by using offline analysis (Osiris Imaging Software 3.6; University of Geneva, Geneva, Switzerland) of the frontal or right anterior oblique aortograms. 
The morphometric study was performed nonblinded by the authors (R.F., A.G., and A.T.), and the remaining 20 patients were excluded because of the poor quality of their angiographic imaging. All values were normalized to the size of the descending aorta well beyond the isthmus. Furthermore, measurement of the distance between the STJ, the sinus, and the plane of the semilunar valves (Figure 1) was attempted in an additional small subgroup of cases (7 patients) with late-onset NeoAR (more than 2 years after ASO) and with digitally stored optimal angiographic images. These were compared with the results obtained from the same calculations made on postoperative angiograms of 17 children without NeoAR.

\section{Statistical Analysis}

The modified Cox multivariate regression method was used for analysis of the time-related factors provided that the single variable was associated with at least 5 events. Univariate analysis was performed by the 2-tailed Fisher exact test for categorical variables, and the Mann-Whitney $U$ test was used in the case of continuous variables. The variables considered for the study were weight at operation, year of operation (1987 to 2000), pulmonary artery banding before corrective operation (yes or no), presence of subpulmonary VSD (yes or no), trap-door technique for coronary artery reimplantation (yes or no), and a bicuspid native pulmonary valve (yes or no). The presence of subaortic stenosis was considered only in the univariate study, because too few events were associated with this variable. The proportional hazard assumption was tested and confirmed after graphical comparison from the Kaplan-Meier (product-limit) survival estimates of each single variable. Time zero was the date of the arterial switch repair, and patients were censored at the time of first NeoAR occurrence by echocardiography. Progression of NeoAR was studied by means of the Friedman test. The SPSS PC 8.0 (SPSS Inc, Chicago, Ill) software package was used for the appropriate calculations. Descriptive statistics are summarized as the mean and SD or median for continuous variables and as frequencies and percentages for categorical variables.

\section{Results}

The median age at ASO was 8 days (range, 2-344 days). One hundred thirty-six patients had transposition with intact ventricular septum, 33 had transposition with VSD (TGAVSD), and 4 had a double-outlet right ventricle with subpulmonary VSD. In 8 patients, the repair was staged by preliminary pulmonary artery banding. The median follow-up time was 8.2 years (range, 0.6-11.2 years).

Sixty-one patients $(35 \%)$ had Doppler or angiographic evidence of NeoAR. The Kaplan-Meier plot for freedom from postoperative valvular incompetence is shown in Figure 2. No surgical period could be isolated during the entire experience (Figure 3 ). Eleven patients (18\% of the NeoAR group) had trivial to mild valvular incompetence during the early postoperative phase. In one patient, a progressive valvular dysfunction was noted at 10 years of age, whereas all the others were free from NeoAR at discharge and developed regurgitation between 2 and 5 years after the operation.

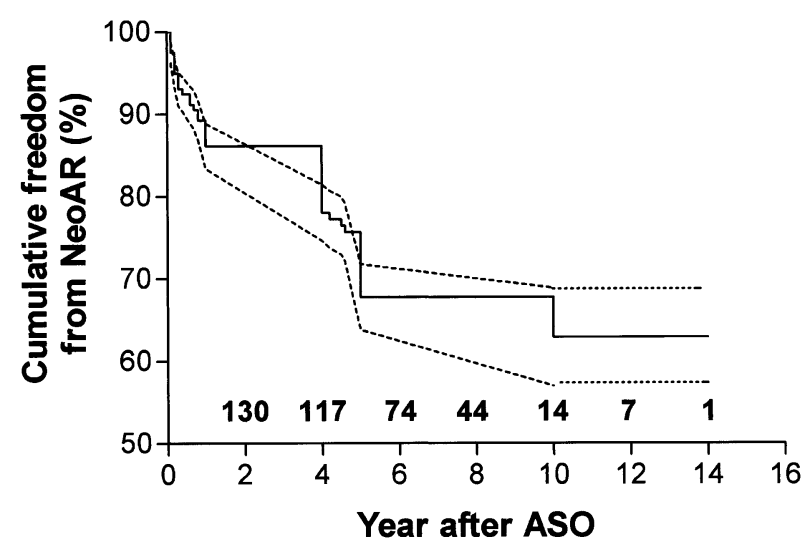

Figure 2. Cumulative freedom from neoaortic regurgitation after arterial switch operation. ASO, Arterial switch operation. The numbers at risk are shown above the $x$-axis.

Univariate analysis showed no demographic difference between patients with and without NeoAR (Table 1). Fortyseven patients showed stable findings throughout the entire follow-up period, with no progression toward higher degrees of valvular incompetence. In this group, regurgitation was trivial in 30 cases and mild in 17. Valvular dysfunction was progressive in 14 patients $(22.9 \%)$, trivial to mild in 11 $(18.0 \%)$, mild to moderate in $1(1.6 \%)$, and trivial to severe in $2(3.3 \%)$. In this group, 2 children needed surgical reintervention on the neoaortic valve: (1) a 31-month-old male infant with TGA-VSD who had had primary ASO with trap-door coronary translocation and who died at 36 months of age after an attempt at neoaortic valve plasty and (2) a 13-year-old boy who had undergone primary repair for simple TGA with the usual coronary arteries and a normally competent neoaortic valve until the age of 10 years, when NeoAR was reported for the first time. At 14 years of age, he needed insertion of a No. 21 mechanical prosthesis (Sulzer Carbomedics, Inc, Zürich, Switzerland) because of a steady increase of the regurgitant fraction.

\section{Predictive Factors}

The results concerning the continuous and dichotomous variables associated with the onset of NeoAR are shown in Table 2.

Weight at operation. There were no differences between the 2 groups by either the univariate or multivariate analysis (relative risk [RR], 0.97; 95\% confidence interval [CI], 0.69-1.35).

Year of operation. The year of operation had no significant effect on the regression model $(P=.13$; RR, 0.98; 95\% CI, 0.96-1.31).

Previous palliation. NeoAR was recognized in 1 of the 8 patients who had 2-stage ASO (12.5\%), versus 60 in the group with primary repair $(36.3 \%)$, with no difference by 


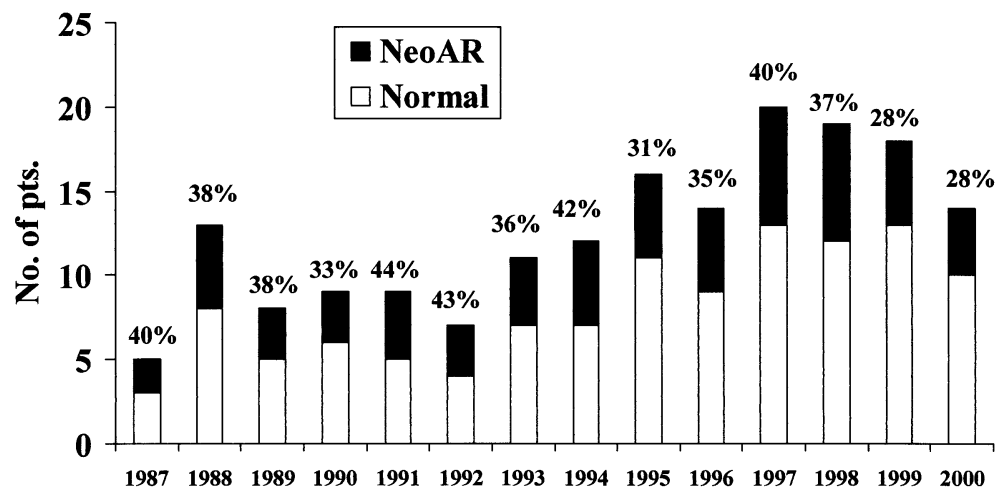

Year of ASO

Figure 3. Time distribution of NeoAR from 1987 to 2000. The numbers above the bars show the yearly prevalence of NeoAR.

TABLE 1. Demographic data within the single subgroups

\begin{tabular}{lccc}
\hline Variable & Without NeoAR & With NeoAR & P value \\
\hline Age at repair $(\mathrm{d})$ & Mean, $15 \pm 28 ;$ median, 7.0 & Mean, 30 \pm 80; median, 8.0 \\
Weight at repair $(\mathrm{kg})$ & Mean, $3.5 \pm 10 ;$ median, 2.9 & Mean, 3.2 $\pm 9.1 ;$ median, 3.1 & .17 \\
Male/female ratio & 0.4 & 0.5 & .84 \\
\hline
\end{tabular}

TABLE 2. Anatomic and surgical risk factors for NeoAR

\begin{tabular}{lcccc}
\hline Parameter & $\begin{array}{c}\text { Without } \\
\text { NeoAR }\end{array}$ & $\begin{array}{c}\text { With } \\
\text { NeoAR }\end{array}$ & $\begin{array}{c}\text { Univariate } \\
\text { analysis }(\boldsymbol{P})\end{array}$ & $\begin{array}{c}\text { Multivariate } \\
\text { analysis }(\boldsymbol{P})\end{array}$ \\
\hline Weight at ASO $(\mathrm{kg})$ & $3.5 \pm 1.0$ & $3.2 \pm 9.1$ & .84 & .86 \\
Previous PAB & $6(5.3 \%)$ & $2(3.3 \%)$ & .82 & .11 \\
Subpulmonary VSD & $46(41 \%)$ & $17(28 \%)$ & .14 & .18 \\
$\begin{array}{l}\text { LVEF <50\% at last } \\
\quad 2(1.8 \%)\end{array}$ & $1(1.6 \%)$ & .82 & - \\
$\quad$ follow-up & & & & \\
$\begin{array}{l}\text { Complex coronary } \\
\quad \text { pattern }\end{array}$ & $13(11.4 \%)$ & $2(3.8 \%)$ & .22 & - \\
$\begin{array}{l}\text { Trap-door technique } \\
\text { Bicuspid PV }\end{array}$ & $34(30.3 \%)$ & $42(68.8 \%)$ & .0002 & .0005 \\
$\begin{array}{l}\text { Aortic coarctation/ } \\
\quad \text { interruption }\end{array}$ & $2(1.8 \%)$ & $4(4.9 \%)$ & .5 & .6 \\
$\begin{array}{l}\text { Left ventricular } \\
\quad \text { outflow tract } \\
\quad \text { obstruction }\end{array}$ & $2(3.2 \%)$ & $2(3.2 \%)$ & .94 & - \\
\hline
\end{tabular}

$A S O$, Arterial switch operation; $P A B$, pulmonary artery banding; $L V E F$, left ventricular ejection fraction; $P V$, pulmonary valve.

univariate or multivariate analysis $(\mathrm{RR}, 2.3 ; 95 \% \mathrm{CI}$, $0.78-8.30)$.

Ventricular function. Ventricular function was mildly depressed in 2 patients with a normal neoaortic valve, versus 1 in the NeoAR group, without statistical significance by univariate analysis.

Ventricular anatomy. A large VSD or a Taussig-Bing anatomy was a common finding in the NeoAR group, whereas an intact septum was more frequent within the group with a competent neoaortic valve. However, the multivariate study showed that the difference between the 2 groups could be due to chance ( $P=.18 ; \mathrm{RR}, 1.5 ; 95 \% \mathrm{CI}, 0.82-2.76)$.

Coronary anatomy. Complicated coronary patterns were more common in the group without NeoAR, but this difference could be due to chance $(P>.2)$.

Coronary relocation technique. Coronary reimplantation by trap-door technique was a frequent finding among patients with NeoAR $(68.8 \%$ vs $30.1 \%$ in the control group), as confirmed by the univariate study. This finding was even more important after multivariate analysis, which showed the trap-door technique as a strong predictive factor for the onset of NeoAR (RR, 3.48; 95\% CI, 1.91-6.36).

Bicuspid valve. A bicuspid pulmonary valve was found in only 5 cases and was not correlated with the onset of NeoAR (RR, 1.46; 95\% CI, 0.34-6.16).

Aortic interruption or coarctation and left ventricular outflow tract obstruction. The univariate analysis showed no correlation between neoaortic valvular function and surgical repair of interruption or coarctation of the aortic arch or preoperative evidence of mild left ventricular outflow tract obstruction.

\section{Morphometric Analysis}

Among the patients with available morphometric analysis, 59 had NeoAR, and 72 had a competent semilunar valve. There were no differences between the 2 groups in the 
widths of single segments of the neoaortic root. However, the ratio between the diameter of the sinotubular ridge and the maximum diameter of the neoaortic sinus was higher in the patients with NeoAR than in the control group (Table 3). The graphical reconstruction of the neoaortic root, based on diameters measured on the angiographic pictures, shows that the patients with NeoAR usually have an elongated neoaortic root with a smooth transition from the sinus to the ascending aorta and a flattened STJ (Figures 4 and 5). Moreover, the STJ seems displaced, with an increased distance from the sinuses of Valsalva (Table 3 and Figure 5).

\section{Discussion}

This study, with a $35 \%$ prevalence of post-ASO NeoAR and other similar, although sporadic, observations, ${ }^{12,13}$ provides grounds for increased awareness of a commonly underestimated complication of anatomic repair of TGA and sets forth new worries for the long-term prognosis of ASO patients.

The 2 variables expected to play a role in the development of NeoAR-ie, previous pulmonary artery banding $^{14,15}$ and the presence of bicuspid pulmonary valve ${ }^{16}$ did not reach statistical significance in our series. However, the small number of patients with a 2-stage repair and the surprisingly low incidence of bicuspid pulmonary valve in our population may account for this lack of correlation. However, although the issue of pulmonary artery banding is further restricted to a few selected patients undergoing 2-stage ASO, the presence of a bicuspid native pulmonary valve should prompt some caution, at least according to studies on the natural history of the bicuspid aortic valve. ${ }^{16}$

These data do not clarify whether progressive dilatation of the neoaortic root may cause failure of leaflet coaptation, as suggested by Marino and associates. ${ }^{17}$ In fact, we found no correlation between NeoAR and absolute sizes of the neoaortic root segments. This piece of evidence led us to speculate that the late onset of aortic regurgitation may be induced, instead, by a complex rearrangement of the STJ geometry, and the differences we found in the height of the STJ and in the STJ/sinus ratio seem to support this hypothesis. The graphical reconstruction of the neoaortic root in post-ASO patients with and without NeoAR compared with the geometry of a normal aorta as described by Kunzelman and colleagues ${ }^{11}$ possibly explains how subtle morphofunctional differences between the 2 groups of our series may affect the delicate ergonomic interaction and permit coalescence of the 3 aortic cusps. In fact, there is a proven role of the 3-dimensional anatomy of the aortic root in healthy subjects versus that in patients with chronic aortic regurgitation, ${ }^{18-21}$ and this role is indirectly substantiated by the success of valve-sparing surgical techniques by David and Feindel, ${ }^{22}$ although their study was in adult patients. Unfortunately, we were not able to track the variation of root
TABLE 3. Morphometric analysis of the neoaortic root at different levels

\begin{tabular}{lccc}
\hline Parameter & $\begin{array}{c}\text { Without } \\
\text { NeoAR }\end{array}$ & $\begin{array}{c}\text { With } \\
\text { NeoAR }\end{array}$ & $\begin{array}{c}\text { Univariate } \\
\boldsymbol{P}\end{array}$ \\
\hline STJ/sinus ratio & $0.7 \pm 0.3$ & $0.8 \pm 0.3$ & .03 \\
Upper sinus height & $0.7 \pm 0.2$ & $0.9 \pm 0.2$ & .0001 \\
Lower sinus height & $0.6 \pm 0.3$ & $0.5 \pm 0.2$ & .09 \\
Ascending aorta & $1.4 \pm 0.3$ & $1.5 \pm 0.4$ & .2 \\
STJ & $1.6 \pm 0.4$ & $1.7 \pm 0.3$ & .06 \\
Sinus & $2.2 \pm 0.2$ & $2.1 \pm 0.5$ & .06 \\
Neoaortic valve & $1.5 \pm 0.4$ & $1.6 \pm 0.4$ & .29 \\
\hline
\end{tabular}

The values are unitless and represent the diameter of the neoaortic root normalized against the normal descending aorta.

dimensions because of the lack of precise echocardiographic measurements in all patients across the entire experience; this limited our capability to provide a more comprehensive analysis of the potential interrelations between coronary reimplantation techniques and aortic morphology.

The reason why NeoAR seems to appear with increasing frequency 2 to 4 years after the operation in subjects with an otherwise perfectly functional postoperative neoaortic valve is still unclear. Although other studies concerning the size and growth of the neoaortic root and anastomosis have been published, ${ }^{22-24}$ the simple measurement of the diameter of the vascular structures may be insufficient to outline the complex geometric modifications of the growing neoaortic root after ASO. Indeed, the late occurrence of NeoAR in many patients and the results of the morphometric study suggest that the neoaortic root distortion should not be regarded as the result of a direct surgical injury but rather as an effect of some degree of growth impairment, which is possibly magnified by the extensive remodeling caused by the opening of the trapdoors. Furthermore, we cannot rule out a role of the discrepancy in caliber between the native aortic and pulmonary roots, eg, in the cases with TGA-VSD and aortic coarctation.

This was a retrospective study and shares all the limitations of similar inquiries. Potential criticism may also be stimulated by the risk of underestimating time-related factors concerning the surgical technique. In this case, the trap-door coronary reimplantation could have been associated with the initial ASO experience; thus, it would be correlated with the learning curve for this operation rather than being an independent variable (an alfa-zero error). However, both types of coronary techniques (trap-door and punch reimplantation) were evenly distributed across the entire experience, thus limiting the potential effect of the learning curve. Other interesting variables were not included in this study for lack of reliable retrospective information. Among these, the relative size and spatial relationship of the native pulmonary and aortic valve would have 

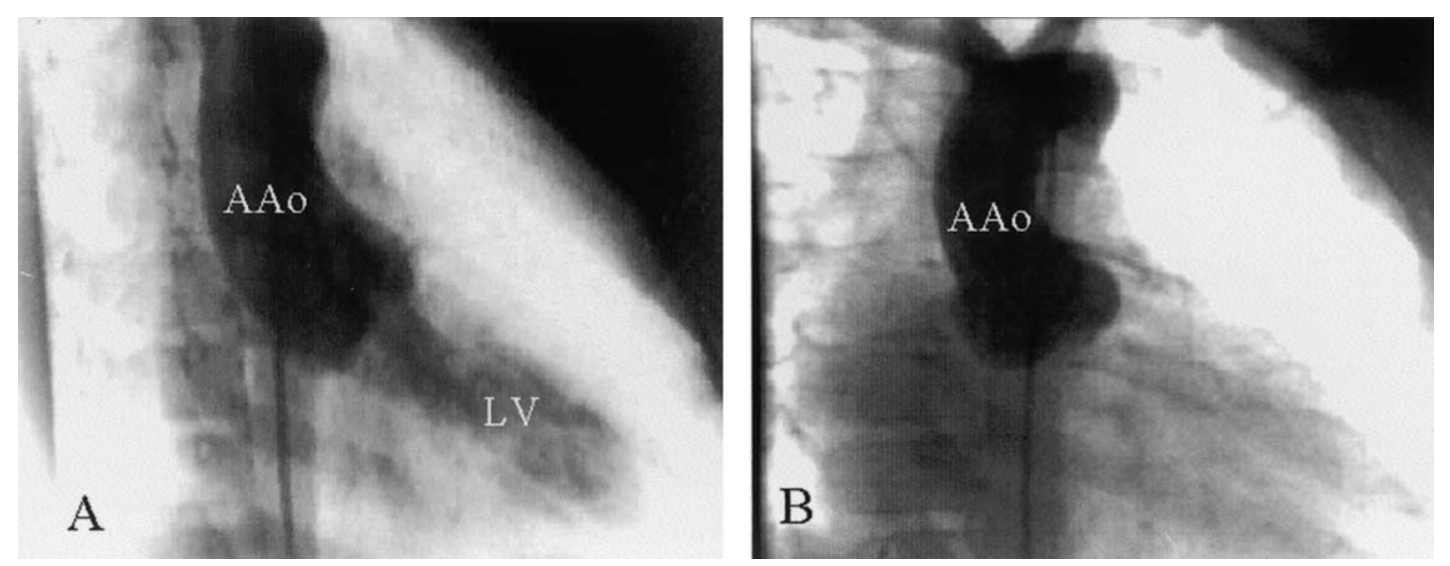

Figure 4. Postoperative angiograms of the neoaorta showing a typical case of late-onset neoaortic regurgitation (A) and another one with a perfectly competent systemic semilunar valve (B). Note the smooth and elongated shape of the case in panel $A$ in contrast to the well-defined sinotubular junction of the patient depicted in panel $B$. $A A O$, Ascending aorta; $L V$, left ventricle.

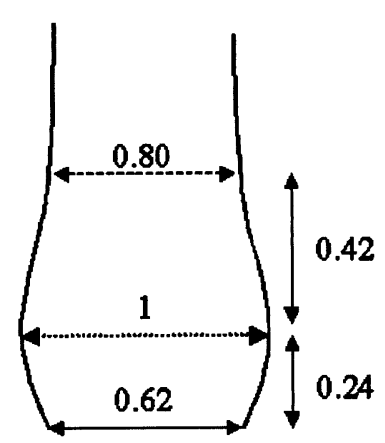

With NeoAR

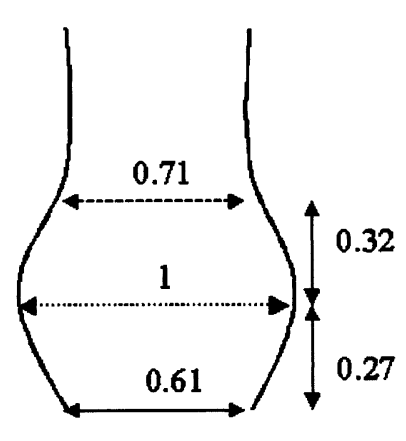

Without NeoAR

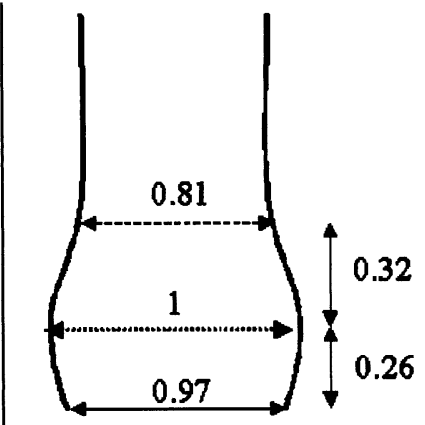

Normal aortic root

Figure 5. Shape of the neoaortic root of the patients with and without NeoAR. The normal human aortic root (modified from Kunzelman and colleagues ${ }^{11}$ ) is shown for comparison. The sinus diameter is represented by a value of 1 , and all other values are represented by a fraction of this number. The figures are not in scale and are meant only to give information about the shape of the root.

been significant and deserve further consideration. Moreover, the morphometric study may have been influenced by the nonblinded measurements performed by the authors. A mild overestimation of the NeoAR prevalence should also be taken into account, because we cannot exclude the presence of cases with a native incompetent pulmonary valve that may have gone undetected or simply unreported in the preoperative study, thus unrelated with any type of surgical procedure. However, because the number of patients with valvular regurgitation at discharge was limited (18\% of the NeoAR group), this should be only a minor issue.

\section{Conclusions}

In conclusion, NeoAR is probably the result of a multifactorial process for which STJ geometry and surgical tech- nique are some of the mechanisms involved. Even if increasing in incidence over time, NeoAR is often a stable condition, at least during the first 10 years. The trap-door type of coronary reimplantation is associated with an increased risk for NeoAR. Therefore, we endorse this option for coronary reimplantation only in those cases with the most complicated coronary patterns.

\section{References}

1. Jatene AD, Fontes VF, Paulista PP, Souza LCB, Neger F, Galantier M, et al. Anatomic correction of transposition of the great vessels. J Thorac Cardiovasc Surg. 1976;72:264-70.

2. Boenhoffer P, Bonnet D, Piechaud JF, Stumper O, Aggoun Y, Villain $\mathrm{E}$, et al. Coronary artery obstruction after arterial switch operation for transposition of the great arteries in newborns. J Am Coll Cardiol. 1997;29:202-6. 
3. Hauser M, Bengel FM, Kuhn A, Sauer U, Zylla S, Braun SL, et al. Myocardial blood flow and flow reserve after coronary reimplantation in patients after arterial switch and Ross operation. Circulation. 2001; 103:1875-80.

4. Martin MM, Snider AR, Bove EL, Serwer GA, Rosenthal A, Peters J, et al. Two-dimensional and Doppler echocardiographic evaluation after arterial switch repair in infancy for complete transposition of the great arteries. Am J Cardiol. 1989;63:332-6.

5. Williams WG, Quaegebeur JM, Kirklin JW, Blackstone EH. Outflow obstruction after the arterial switch operation: a multiinstitutional study. J Thorac Cardiovasc Surg. 1997;114:975-90.

6. Nogi S, McCrindle BW, Boutin C, Williams WG, Freedom RM, Benson LN. Fate of the neopulmonary valve after the arterial switch operation in neonates. J Thorac Cardiovasc Surg. 1998;115:557-62.

7. Santoro G, Di Carlo D, Formigari R, Ballerini L. Late onset pulmonary valvar stenosis after arterial switch operation for transposition of the great arteries. Heart. 1998;79:311-2.

8. Haas F, Wottke M, Poppert H, Meisnert H. Long-term survival and functional follow-up in patients after the arterial switch operation. Ann Thorac Surg. 1999;68:1692-7.

9. Galassi AR, Nihoyannopoulos P, Pupita G, Odawara H, Crea F, McKenna WJ. Assessment of colour flow imaging in the grading of valvular regurgitation. Eur Heart J. 1990;11:1101-8.

10. Martin RP, Ettedgui JA, Qureshi SA, Gibbs JL, Baker EJ, RadleySmith R, et al. A quantitative evaluation of aortic regurgitation after anatomic correction of transposition of the great arteries. J Am Coll Cardiol. 1988;12:1281-4.

11. Kunzelman KS, Grande KJ, David TE, Cochran RP, Verrier ED. Aortic root and valve relationships. Impact on surgical repair. J Thorac Cardiovasc Surg. 1994;107:162-70.

12. Imamura M, Drummond-Webb JJ, McCarthy JF, Mee RBB. Aortic valve repair after arterial switch operation. Ann Thorac Surg. 2000; 69:607-8.

13. Yoshizumi K, Yagihara T, Uemura H. Approach to the neoaortic valve for replacement after the arterial switch procedure in patients with complete transposition. Cardiol Young. 2001;11:666-9.

14. Gibbs JL, Qureshi SA, Wilson N, Smith RR, Yacoub MH. Doppler echocardiographic comparison of haemodynamic results of one- and two-stage anatomic correction of complete transposition. Int J Cardiol. 1988;18:85-92.

15. Gibbs JL, Qureshi SA, Martin R, Wilson N, Yacoub MH, Smith RR. Neonatal anatomical correction of transposition of the great arteries: non-invasive assessment of haemodynamic function up to four years after operation. Br Heart J. 1988;60:66-8.

16. Keane MG, Wiegers SE, Plappert T, Pochettino A, Bavaria JE, St. John Sutton MG. Bicuspid aortic valves are associated with aortic dilatation out of proportion to coexistent valvular lesions. Circulation. 2000;102(suppl 3):III35-9.

17. Marino BS, Wernovsky G, Kreb DL, Mantel SF, van der Woerd W, Visser D, et al. Neo-aortic root dilation and regurgitation are progressive following the arterial switch operation. J Am Coll Cardiol. 2002; 39:413A.

18. Bellhouse BJ, Bellhouse F, Abbott JA, Talbot L. Mechanism of valvular incompetence in aortic sinus dilatation. Cardiovasc Res. 1973;7:490-4.

19. Frater RW. Aortic valve insufficiency due to aortic dilatation: correction by sinus rim adjustment. Circulation. 1986;74(3 Pt 2):I1136-42.

20. Furukawa K, Ohteki H, Cao Z, Doi K, Narita Y, Minato N, et al. Does dilatation of the sinotubular junction cause aortic regurgitation? Ann Thorac Surg. 1999;68:949-54.

21. Dagum P, Green RG, Nistal FJ, Daughters GT, Timek TA, Foppiano $\mathrm{LE}$, et al. Deformational dynamics of the aortic root. Modes and physiologic determinants. Circulation. 1999;100(suppl 2):II54-62.

22. David TE, Feindel CM. An aortic valve sparing operation for patients with aortic incompetence and aneurysm of the ascending aorta. J Thorac Cardiovasc Surg. 1992;103:617-22.

23. Hourihan M, Colan SD, Wernovsky G, Maheswari U, Mayer JE, Sanders SP. Growth of the aortic anastomosis, annulus, and root after the arterial switch procedure performed in infancy. Circulation. 1993; 88:615-20.

24. Hutter PA, Thomeer BJM, Jansen P, Hitchcock JF, Faber JAJ, Mejiboom EJ, et al. Fate of the aortic root after arterial switch operation. Eur J Cardiothorac Surg. 2001;20:82-8. 